\title{
Study on Course Teaching of Software Engineering Majors based on Workshop Mode
}

\author{
SHI Chun ${ }^{1, a}$, HE Shuqian $^{1}$, DENG Zhengjie ${ }^{1}$ and ZHOU $\mathrm{Qi}^{2, b^{*}}$ \\ ${ }^{1}$ School of Information Science \& Technology, Hainan Normal University, Haikou 571158, R.P.China \\ ${ }^{2}$ Guangdong Polytechnic Vocational College, Guangdong Radio \& TV University, Guangzhou \\ 510091, R.P.China \\ abyshichun@126.com, b124358919@qq.com \\ *corresponding author
}

Keywords: workshop mode; teaching innovation; software engineering; practice teaching.

Abstract. The close combination of theoretical teaching with practical teaching is a characteristic of software engineering majors and it is a difficult problem to enhance the practical teaching during the teaching processes. Aiming at different courses over stressing theoretical teaching or practical teaching, we propose some feasible teaching design schemes of specialized courses based on workshop mode, which includes the organization of study teams, methods of solving problems, technique of communication and establishment of cognitive system. The good experiment effect has been proved effective in teaching processes.

\section{Introduction}

University classroom is an important place for teaching activities and students' learning; it is the main way for college students to acquire knowledge. Classroom teaching has a direct impact on program benefits and affects ultimately the quality of talent cultivation, and also embodies the idea of higher education.

According to the center around the teaching activity, the classroom teaching is divided into two types, 'Teacher centered' and 'student centered' [1]. In activities of the teacher- centered classroom, the teacher is the focus of the class, playing a leading role in the whole process of teaching. Teachers generally use the mandatory teaching method, imparting knowledge and skills to the students. It is usually like a one-way broadcast mode. In activities of the student-centered classroom, students often at the center of it. Teachers interact with equal status with the students. The teaching process emphasizes active learning and deep understanding of students on learning subject. At this time, teachers usually play counseling, tutoring and learning motivation of the role. The modern teaching activities usually emphasized the interaction between teachers and students, imparting knowledge in classroom teaching more effectively. In this process, teachers need to be in a good way and attitude help students establish their own cognitive systems. Therefore, in the classroom teaching activities, teachers' 'teaching' and 'learning' of the students is an indivisible part. How to mobilize the enthusiasm of the students with a good teaching way is the key to the completion of a high quality of classroom teaching.

Characteristics of software engineering are mainly embodied in: practical, engineering, systematic, comprehensive and composite foundation, mathematical logic, to cultivate students' ability in engineering practice, the software works and communication skills, etc. In the undergraduate learning stage, due to the dual problems in the rapid development of computer science and are not familiar with knowledge in related fields, students' learning initiative is constrained. At the same time, students usually do not establish their own cognitive systems and the shortage of programming experience all restrict the students' manipulative ability and oral expression ability. It is shown obviously that they are not active in the courses and are not high in teachers' enthusiasm, and even the emergence of negative silence in class [2] [3] [4].

Combines with the 'workshop' practice teaching mode and the software engineering curriculum requirements, through reflection, exploration and the design of classroom teaching activities, 
strengthening the guidance of students in the limited classroom teaching can significantly enhance the enthusiasm of students, improve oral expression ability and communication skills, and further to cultivate students’ program thinking ability and the team cooperation spirit.

\section{'Workshop' practice teaching}

'Workshop', also known as thematic workshops, originated in Bauhaus college in Europe, it has gradually evolved into a practical teaching mode now. The learning process is like 'factory apprentice', student status is 'the apprentice'. In the process of teaching, teachers as a form of art courses called 'Form Tutor', they teach theoretical courses and guide the students' professional development. Teachers as the technology, arts and crafts production course teacher called 'Studio Master', responsible for the guide of practice teaching. The teaching methods used by Bauhaus college form a three-in-one modern design education mode of teaching, research and practice. Teaching provides service for research and practice, research provides theoretical guidance for teaching and practice, practice provides validation for teaching and research. 'Workshop' teaching model made knowledge and technology is both important, also the theory and practice of synchronization. It provides a whole process for students to know the theoretical knowledge they have studied inside out.

'Workshop' teaching mode emphasizes to take the student as the center. Pay attention to students' needs, intrinsic motivation and give full play to students' autonomous learning. Pay attention to the cultivation of students finding and solving problems as well as the ability on knowledge and skills' application. At the same time, the teaching mode emphasizes the multiple ways to share and show results of the theories contact facts. It is a way that not only pays attention to process but also to the result. Generally speaking, 'workshop' teaching mode is some small groups discuss a topic though some ways, like activities, discussion and short talks with a core of the speakers' guide. The essence of 'workshop' teaching mode is to promote students 'learning by doing', in line with the 'practice-cognition-practice again'. As a kind of teaching way, it can promote the interaction between teachers and students, arousing the enthusiasm of classroom participation[5].

\section{'Workshop’ practice teaching design on Software Engineering Majors}

According to the software engineering undergraduate curriculum, from the emphasis on theory teaching to experimental teaching, select the 'Design and Analysis of Computer Algorithm (Algorithm Design and Analysis)' and 'Oracle'. According to the ways of team construction methods and the corresponding teaching method from the 'workshop' teaching mode, I have made a series of exploration and design.

Design on 'Algorithm Design and Analysis'. 'Algorithm Design and Analysis' [6] is an important professional course in computer science and software engineering, it describes solutions for typical non numerical computational problems in software development, require students to master the basic principle, method and technology of algorithm. How to make students master the internal connection between the algorithm and the characteristics of the algorithm is the focus of the teaching in the limited teaching time. Based on knapsack problem and 0-1 knapsack problem [7], we explore the specific content of the 'workshop' practice teaching design. Knapsack problem and 0-1 problem requires students to distinguish the difference between the two algorithms and constraints on the program design. Therefore, we can determine the core knowledge points: (1) The similarities and differences of knapsack problem and 0-1 knapsack problem, and the conversation conditions (2) The two problems' differences in program design and transformation. In teaching process, students are required to prepare materials around the core of knowledge and explain in class. The teaching process is as follows:

Firstly, we divide students into small groups. The students volunteered to combine with other 3 to 4 people, and they should choose a leader and a spokesman in different person. A requirement of team leader is to divide the work, and the spokesman needs to collect materials and prepare for logical 
sequence of explaining. On one hand, the purpose of team division is to train students in the spirit of cooperation, on the other hand, is to reduce pressure for the new content preparation.

Secondly, the multi groups prepare for the same topic. Make 2 or 3 groups prepare for a same topic and explain it. Although the points will be similar, but different team's focus will be slightly different, and their ways of expression will be different. On the one hand, students could have more chance to exercise the organization ability, oral expression ability and logical thinking ability in this way, on the other hand, differences among the different team will allow student to further deepen the comprehensive understanding of the problem.

Finally, it's the teacher's comment. It is also the key link of teaching. Teachers need to summarize the conditions of students' preparation for materials and their lectures. On the one hand, it needs to cover the points, on the other hand also to comment on each group's explain, to let the students participate in evaluation more. The purpose of teacher's comment is to guide the students to analysis and solve problems correctly.

Design on 'Oracle Database'. ' 'Oracle Database' is a professional course in Software Engineering, the use of SQL language is one of the focus of the course. I designed two tasks in the teaching process: (1) Write a SQL program to read data from a text file and write in the database table, mainly to strengthen the proficiency of students for the SQL statement, as well as function, process and trigger. (2) Write experiment reports, requiring the system development needs requirements analysis, program analysis design, implementation and the results.

According to the teaching schedule, test and report writing time is approximately a week (classroom teaching class is 10 classes). During this time, with a certain degree of difficulty, students need to be familiar with the software environment, complete SQL programming and writing reports. Therefore, in the process of teaching, I made a specific design of the 'workshop' practice teaching mode. The specific contents are as follows:

Firstly, we divide students into small groups. The students volunteered to combine with other students. The team members were with a minimum of 4 people and a maximum of 9 people at last. Since there are no special requirements for reporting mode, each group only set a leader; it is convenient for teacher to know the conditions of team cooperation and task completion.

Secondly, it is problem solving. In the process of practical teaching, teachers won't give the answer directly for students' question. Teachers will guide the students how to use the web to find the corresponding solutions, and let the team to discuss with each other to determine the final feasible scheme. According to the specific problems, teachers encourage team members to complete the solution after class.

Then, it is process inspection. Through communication with different team, teachers selected teams that have characteristics, team members will give lectures not regularly, and they will introduce the team division, implementation procedures and report writing ideas and show relevant information. For example, according the two functions of read a text file and parse the data information, I arrange students to introduce the program content they have discussed, and show the preliminary effect.

Finally, it is the teachers' comment. On the one hand, the teacher needs to summarize the conditions that students have completed and to further clarify the experimental contents and requirements, on the other hand, teachers will give some suggestions to students for future, combined the software engineering development requirements.

According to the result, the way to divide students into small teams provides some reference for the practice teaching activity. To organize a team should consider the difficulty of specific task and the leader's ability. Each team number can't be too much when the task is not particularly serious. In the practice of teaching activities, less number of teams (for example, a team of 4 people) organizational capacity are relatively strong, programming and documentation are relatively clear division, got good effect. But some larger team (team consisting of 9 people), leader complained about there were no students participate in it. In view of this situation, teachers should know the 
feedback in teaching activities, and dissolute the team to complete the task when the staff degree is not high.

In the practice of teaching activities, teachers can guide students to master the method of solute problems, aiming at specific problems. On the one hand, this way can enhance student's communication skills and team spirit; on the other hand, it also can greatly improve the learning enthusiasm of students and make students grasp the knowledge faster.

\section{Summary}

It had been said 'the purpose of teaching is to cultivate the students' own learning, do their own research, use their own mind to think, see with their own eyes, with their own hands to do this kind of spirit.'

In order to enhance the enthusiasm of students to participate in teaching activities, also in order to carry on the practice teaching, aiming at the characteristics of professional courses of software engineering, analysis of the 'workshop' practice teaching mode, I put forward some feasible 'workshop' practice teaching design of professional courses. The design has analysis of organizing teams and team spirit, the number of members and the leader's ability need to be considered. Guide the students to solve problems by themselves, training the ability of logical thinking, improve communication skills. Students should think first and teachers give advice, it can effectively cultivate and establish their own cognitive system. Through the way that part of teams discuss the same topic, teachers could know about students and adjust teaching corresponding design scheme based on the feedback information. Teaching effect shows that good 'workshop' practice teaching corresponding design scheme can effectively cultivate students' creative thinking and good oral expression ability, enhance the team spirit and further strengthen the students' observation, analysis and problem solving ability at the same time.

\section{Acknowledgements}

This work was financially supported by NSFC (No.61362016), NSF of Hainan Province (No.613163, No.613164, and No.612122 ).

\section{References}

[1] Classification of Classroom Teaching Model, http://wenku.baidu.com/view/0acdb692daef 5ef7ba0d3c45.html. March, 2014.(in chinese)

[2] WEI Ping, Thinking about Teaching of University Classroom, Science Information, 2010 (030): I0396-I0396.

[3] LI Xue, HU Shiqi, LI Binghuang, Progress and Reflection about the Study of University Classroom Instruction within Recent Ten Years: A Case Study of the CNKI's Papers. Journal of Hunan University of Science \& Technology (Social Science Edition), 15(3):142-145,2012.

[4] WANG Jiang, ZHANG Jing, Dealing with a Silent College EFL Class, China University Teaching, 2008, 1:81-84.

[5] XIAO Hong, Apllication of Translation Workshop Approach to Translation Teaching, Journal of Sichuan International Studies University, 21(1):139-142, 2005.

[6] ZHENG Hong, SHAO Zhiqing, FU Haibo, First Step towards the Teaching Reform of Algorithm Design and Analysis, Computer Education, 2008(014):29-30.

[7] WANG Xiaodong, The Design and Analysis of Computer Algorithm, Publishing House of Electronics Industry, 2007.

[8] ZHANG Lijun, Exploration on Teaching Design Patter Course, Computer Education, 2010(004):66-68. 